Check for updates

Cite this: RSC Adv., 2018, 8, 37631

Received 6th September 2018 Accepted 17th October 2018

DOI: $10.1039 / c 8 r a 07450 j$

rsc.li/rsc-advances

\section{Synthesis and application of aminophenyl-s- triazine derivatives as potential flame retardants in the modification of epoxy resins}

\author{
Haiyang Wu, Rong Hu, Birong Zeng, (D) * Li Yang, Ting Chen, Wei Zheng, Xinyu Liu, \\ Weiang Luo and Lizong Dai (D) *
}

In order to develop new phosphorus-nitrogen-containing flame retardants, three novel compounds of DOPO-substituted aminophenyl-s-triazine (TAT-DOPO) with different $\mathrm{P} / \mathrm{N}$ element ratios were synthesized by Kabachnik-Fields reaction. TAT-triDOPO possessing three DOPO units in one molecule exhibited the best thermal stability. Besides, TAT-triDOPO and TAT-hexaDOPO possessing active hydrogen displayed the characteristics of reactive-type retardant, while TAT-enneaDOPO without active hydrogen represented additive-type retardant. The influences of three TAT-DOPO compounds on the thermal stability, flame retardancy and mechanical properties of the cured EP composites were investigated. Compared with pure EP, the char yields of EP/TAT-DOPO were increased. The LOI value and the UL-94 ratings of EP/TAT-triDOPO with a $5 \%$ loading were improved to $34.0 \%$ and $\mathrm{V}-0$ grade. The PHRR, THR and HRC of EP/TAT-triDOPO were decreased by $25.7 \%, 21.1 \%$ and $25.4 \%$, respectively. Furthermore, the incorporation of TAT-triDOPO could also improve the flexural strength and elastic modulus of cured EP. It was explained that the existence of active hydrogen atoms within TAT-triDOPO molecule can act as effective chemical cross-linking points in EP network. Finally, based on the SEM and TGA-FTIR analysis of pyrolytic products of cured EP/TAT-DOPO, it was deduced that the prepared TAT-DOPO flame retardant could exhibit both condensed phase and gas phase flame-retardancy mechanism.

\section{Introduction}

As a member of thermosetting resins, epoxy resin (EP) has been widely utilized in the fields of microelectronic packaging materials, surface coatings, adhesives and advanced composite matrices due to its outstanding properties, such as good chemical resistance, satisfactory electrical insulation, excellent mechanical and adhesive properties. ${ }^{1-3}$ But flammability is the main drawback of epoxy resin, which limits its further application in some special fields. ${ }^{4-6}$ Because the use of traditional halogenated flame retardants produce a series of environmental concerns, ${ }^{7,8}$ researching possible halogen-free flame retardants has attracted a great deal of attention. Some organophosphorus compounds, especially 9,10-dihydro-9-oxa-10-phosphaphenanthrene-10-oxide (DOPO) and its derivatives, are known to be a kind of additives with high reactivity and flame-retardant efficiency, having the ability to capture free radicals, quench flames and improve char formation during combustion. ${ }^{9-14}$ But it was reported that the conventional DOPO-modified epoxy resins showed a great decline in thermal properties due to the existence

College of Materials, Fujian Provincial Key Laboratory of Fire Retardant Materials, Xiamen University, Xiamen, Fujian, China 361005. E-mail: brzeng@xmu.edu.cn; lzdai@xmu.edu.cn of weak bonds in flame retardants. ${ }^{15,16}$ Besides, a large loading amount of DOPO may result in the declining in mechanical properties of EP composites. ${ }^{17-19}$ Recently, some compounds containing triazine unit have received much attention due to the excellent charring effect deriving from the abundant nitrogen content. But the efficiency of flame-retardant additive with only nitrogen was low. ${ }^{20}$ Therefore, some new strategies are required to achieve comprehensive functionalities, such as combining nitrogen-containing compounds like polyaniline ${ }^{21-23}$ or triazine and organo-phosphorus together. These flame retardants containing both phosphorus and nitrogen elements are popular because of their high heat resistance ${ }^{24-26}$ and the phosphorusnitrogen synergistic effect. ${ }^{27,28}$ However, few works has been reported to explore the influences of different $\mathrm{P} / \mathrm{N}$ ratios on the performances of cured EP.

In this work, novel DOPO-substituted aminophenyl-striazine (TAT-DOPO) compounds with controllable $\mathrm{P} / \mathrm{N}$ element ratio were synthesized by classical Kabachnik-Fields reaction via the combination of 2,4,6-tris( $p$-aminoaniline)-1,3,5-triazine (TAT), polyoxymethylene (POM), and 9,10-dihydro-9-oxa-10phospha-phenanthrene-10-oxide (DOPO), and were used as flame retardants in the modification of epoxy resins. Following are our considerations on the design of this novel flame retardant system from three perspectives. Firstly, two functional 
flame-retardant units like DOPO structure and triazine group were integrated into one molecule to produce synergistic effect. Secondly, the thermal and flame retardancy as well as mechanical properties of the modified EP/TAT-DOPO composites could be adjusted by the number of DOPO units in the corresponding molecular structure. Thirdly, the type of flame retardants could be changed from reactive-type to additive-type by different $\mathrm{P} / \mathrm{N}$ element ratio and the number of active hydrogen sites. Here, the chemical structures of the synthesized three compounds of TAT-triDOPO, TAT-hexaDOPO and TATenneaDOPO were characterized and verified by NMR, MS and FTIR. Their thermal properties and reactivity were investigated by TGA and DSC. The possible interaction between TAT-DOPO and diglycidyl ether of bisphenol A (DGEBA) was discussed. After incorporating TAT-DOPO into EP matrix, the modified epoxy resins were prepared. The flame retardancy, thermal degradation property and mechanical performance of the cured EP/TAT-DOPO composites were tested by LOI, UL-94, SEM, DMA, TGA-FTIR and three-point bending test etc. The flame retardancy mechanism was also discussed. We hope that TATDOPO compounds could not only improve flame retardancy of the modified EP, but also maintain good thermal and mechanical stabilities.

\section{Experimental section}

\subsection{Materials}

Cyanuric chloride, $p$-nitroaniline, acetic acid, Pd/C, dimethyl formamide (DMF), and DOPO were purchased from Aladdin Reagents Co. Ltd., China. Diglycidyl ether of bisphenol A (DGEBA, trade name E51), a kind of liquid epoxy resin, was supplied by Jinan Qingtian Chemical Co. Ltd., China. 4,4'-Diaminodiphenylmethane (DDM) and polyoxymethylene (POM) were purchased from Sinopharm Chemical Reagent Co. Ltd., China. The reagents used were of analytical grade unless otherwise noted.

\subsection{Synthesis}

(1) Synthesis of 2,4,6-tris( $p$-aminoaniline)-1,3,5-triazine (TAT). The synthetic route of TAT was shown in Scheme 1a. The acetic acid solution of $p$-nitroaniline $(0.045 \mathrm{mmol}, 6.20 \mathrm{~g})$ and cyanuric chloride $(0.01 \mathrm{mmol}, 1.84 \mathrm{~g})$ were mixed together and vigorously stirred for $30 \mathrm{~min}$. The green solid intermediate product was obtained by hot-water washing and suction filtration, and then was introduced into DMF under $\mathrm{N}_{2}$ and heated to $100{ }^{\circ} \mathrm{C}$. When the mixture turned homogeneous, the $\mathrm{Pd} / \mathrm{C}(0.1 \mathrm{~g})$<smiles>COc1cc([N+](=O)[O-])ccc1Nc1nc(Nc2ccc([N+](=O)[O-])cc2)nc(Nc2ccc([N+](=O)[O-])cc2)n1</smiles>

(b)

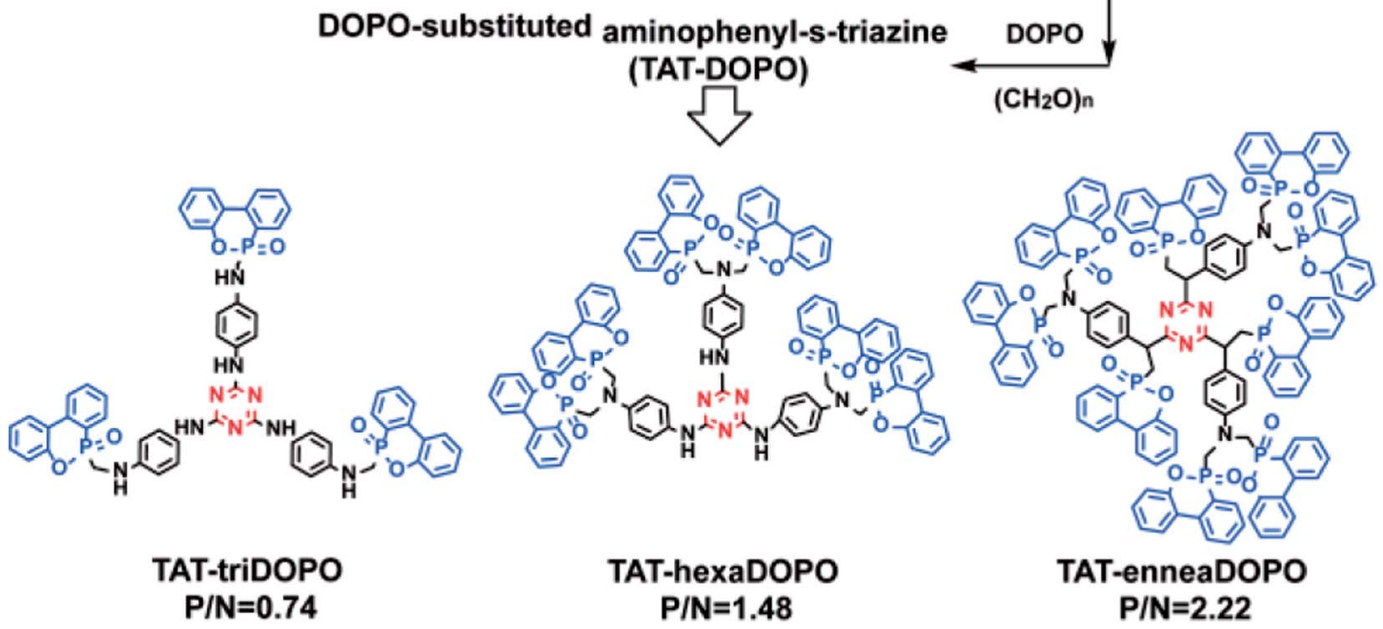

Scheme 1 The synthetic routes of (a) TAT and (b) three TAT-DOPO compounds of TAT-triDOPO, TAT-hexaDOPO and TAT-enneaDOPO with different $\mathrm{P} / \mathrm{N}$ ratio. 
and hydrazine hydrate $(10 \mathrm{~mL})$ were added. After stirring at $100{ }^{\circ} \mathrm{C}$ for $12 \mathrm{~h}$, the mixture was washed with distilled water and the white product of TAT was obtained finally.

TAT: ${ }^{1} \mathrm{H}$ NMR $(\delta$ ppm, DMSO-d 6 ): $8.50(3 \mathrm{H}, \mathrm{Ph}-\mathrm{NH}-\mathrm{Ph}), 7.32$ $\left(6 \mathrm{H}, \mathrm{Ph}-\mathrm{H}_{\mathrm{b}}\right), 6.45\left(6 \mathrm{H}, \mathrm{Ph}-\mathrm{H}_{\mathrm{c}}\right), 4.76\left(6 \mathrm{H},-\mathrm{NH}_{2}-\mathrm{Ph}\right)$.

(2) Synthesis of DOPO-substituted aminophenyl-s-triazine (TAT-DOPO). The synthetic route of TAT-DOPO was shown in Scheme 1b. TAT (1 mmol, $0.399 \mathrm{~g}$ ), DOPO (3 mmol, $0.65 \mathrm{~g})$, POM $(3 \mathrm{mmol}, 0.09 \mathrm{~g})$ and tetrahydrofuran $(150 \mathrm{~mL})$ were introduced into a $250 \mathrm{~mL}$ round-bottom glass flask equipped with a condenser magnetic stirrer and dry nitrogen inlet. The mixture was vigorously stirred at $60{ }^{\circ} \mathrm{C}$ for $48 \mathrm{~h}$ under nitrogen atmosphere. It was concentrated to $10 \mathrm{~mL}$ by vacuum-rotary evaporation and then dropped slowly into ethyl acetate (150 $\mathrm{mL}$ ). A white precipitate was formed and isolated through centrifuge followed by drying under vacuum at $70^{\circ} \mathrm{C}$ for $24 \mathrm{~h}$ to obtain the first kind of flame retardant TAT-triDOPO. As the feed ratio of $[\mathrm{TAT}] /[\mathrm{DOPO}] /[\mathrm{POM}]$ was changed to be $1: 6: 6$ and $1: 9: 9$, the products of TAT-hexaDOPO and TATenneaDOPO were successfully synthesized, respectively.

TAT-triDOPO: ${ }^{1} \mathrm{H}$ NMR $\left(\delta\right.$ ppm, DMSO-d $\left.{ }_{6}\right): 8.69(3 \mathrm{H},-\mathrm{NH}-$ $\mathrm{Ph}), 8.20-7.11(30 \mathrm{H}, \mathrm{Ph}-\mathrm{H}), 6.60(6 \mathrm{H}, \mathrm{Ph}-\mathrm{H}), 5.51(3 \mathrm{H},-\mathrm{NH}-\mathrm{C})$, 4.06-3.85 (6H, $\left.-\mathrm{CH}_{2}-\right)$; ${ }^{31} \mathrm{P}$ NMR $\left(\delta \mathrm{ppm}, \mathrm{DMSO}^{-} \mathrm{d}_{6}\right)$ : 32.42 .

TAT-hexaDOPO: ${ }^{1} \mathrm{H}$ NMR $(\delta$ ppm, DMSO-d 6$): 8.92(3 \mathrm{H}, \mathrm{Th}-$ $\mathrm{NH}-\mathrm{Ph}), 8.20-6.87$ (54H, Ph-H), 6.62 (6H, Ph-H), 4.02-3.77 (12H, $\left.-\mathrm{CH}_{2}-\right) ;{ }^{31} \mathrm{P}$ NMR $(\delta$ ppm, DMSO-d 6 ): 32.01 .

TAT-enneaDOPO: ${ }^{1} \mathrm{H}$ NMR $\left(\delta\right.$ ppm, DMSO-d $\left.\mathrm{d}_{6}\right): 8.08-7.02$ (78H, Ph-H), 6.61 (6H, Ph-H), 4.68-3.99 (18H, $\left.-\mathrm{CH}_{2}-\right)$; ${ }^{31} \mathrm{P}$ NMR $\left(\delta\right.$ ppm, DMSO- $\left.\mathrm{d}_{6}\right): 31.10$ and 29.23.

\subsection{Preparation of EP/TAT-DOPO thermosets}

The thermosetting flame-retardant epoxy resin samples were prepared via the thermal curing of DGEBA and stoichiometric weight of curing agent. DGEBA and $5 \mathrm{wt} \%$ TAT-DOPO compounds were mixed at $125{ }^{\circ} \mathrm{C}$ under continuous stirring until the mixture became transparent. After the temperature cooled to $85^{\circ} \mathrm{C}$, DDM was added as curing agent. And then the mixture was poured into an aluminium mould once the mixture became homogeneous. A three-step curing procedure was carried out to obtain the thermosetting resins. All samples were thermally cured at $120^{\circ} \mathrm{C}$ for $4 \mathrm{~h}$ followed by $140{ }^{\circ} \mathrm{C}$ for $2 \mathrm{~h}$. They were further post-cured at $180^{\circ} \mathrm{C}$ for $2 \mathrm{~h}$ to ensure the complete curing reaction. Thereafter, all specimens were naturally cooled to room temperature in order to avoid stress cracking. Meanwhile, pure cured epoxy resin was prepared as control samples.

\subsection{Characterization}

Nuclear magnetic resonance $\left({ }^{1} \mathrm{H}\right.$ NMR and ${ }^{31} \mathrm{P}$ NMR) spectra were recorded on a Bruker Advanced II AV400 MHz NMR spectrometer with DMSO as the solvent. Mass spectra (MS) were recorded using an Esquire 3000 plus mass spectrometer (Bruker Daltonics). Attenuated total reflectance Fourier transform infrared (ATR-FTIR) spectra were obtained on a Nicolet Avatar 360 spectrophotometer. Scanning electron microscopy (SEM) images were obtained using an SU-70 microscope. Thermogravimetric analysis (TGA) was performed with a Netzsch STA
409EP by heating from room temperature to $800{ }^{\circ} \mathrm{C}$ at a heating rate of $10{ }^{\circ} \mathrm{C} \min ^{-1}$ under air and nitrogen atmospheres. Differential scanning calorimeter (DSC) was conducted with a Netzsch STA 449C by heating from room temperature to $250{ }^{\circ} \mathrm{C}$ at a heating rate of $10{ }^{\circ} \mathrm{C} \mathrm{min}^{-1}$ under nitrogen atmosphere. The mass of each sample was approximately 4-10 mg. Dynamic mechanical analysis (DMA) was carried out by Netzsch DMA 242E instrument. The limiting oxygen index (LOI) was determined with a JF-3 instrument (Jiangning, China), and the specimen dimensions were $100 \mathrm{~mm} \times 6 \mathrm{~mm} \times 4 \mathrm{~mm}$. The percentage of $\mathrm{O}_{2}$ in the $\mathrm{O}_{2} / \mathrm{N}_{2}$ mixture was taken as LOI value, which was just sufficient to sustain the flame. Vertical burning tests were performed according to UL-94 standard by an instrument of Fire Testing Technology UL-94, England. The average of five measurements was reported as the final results. Microscale combustion calorimeter (MCC) tests were conducted on Fire Testing Technology calorimeter of FAA-PCFC model. Samples of 3-5 mg were heated to $900{ }^{\circ} \mathrm{C}$ at a heating rate of $1{ }^{\circ} \mathrm{C} \mathrm{s}^{-1}$ in a stream of nitrogen flowing at $80 \mathrm{~mL} \mathrm{~min}^{-1}$. Thermogravimetric analysis and infrared spectrometry (TGAFTIR) was performed on TGA Q6500 that was interfaced to the Nicolet Magna IR560 FTIR spectrophotometer. About $10 \mathrm{mg}$ sample was put in an alumina crucible and heated from room temperature to $800{ }^{\circ} \mathrm{C}$ at a heating rate of $10{ }^{\circ} \mathrm{C} \mathrm{min}{ }^{-1}$ under $\mathrm{N}_{2}$ atmosphere. Three-point bending experiments were conducted on an electronic universal testing machine (AGS-X, Shimadzu, Japan). The crosshead speed was $1 \mathrm{~mm} \mathrm{~min}^{-1}$ and the typical dimensions of the sample beams were $120 \mathrm{~mm} \times 10 \mathrm{~mm} \times 5$ mm.

\section{Result and discussion}

\subsection{Structural characterization of TAT-DOPO}

Three novel flame retardants of TAT-DOPO were synthesized via the Kabachnik-Fields reaction. The chemical structures of TATtriDOPO, TAT-hexaDOPO and TAT-enneaDOPO were characterized by ${ }^{1} \mathrm{H}$ NMR, ${ }^{31} \mathrm{P}$ NMR, FTIR and MS. It can be seen from ${ }^{1} \mathrm{H}$ NMR spectra that the signal at $8.81 \mathrm{ppm}$ was assigned to the proton of $\mathrm{P}-\mathrm{H}$ in DOPO (Fig. 1a), and the signal at $4.71 \mathrm{ppm}$ was assigned to $-\mathrm{NH}_{2}$ of TAT (Fig. 1b). Compared with DOPO and TAT, the signal of $\mathrm{P}-\mathrm{H}$ disappeared and the signal of $-\mathrm{NH}_{2}$ shifted to $5.53 \mathrm{ppm}$ for TAT-triDOPO (Fig. 1c), while both the two signals disappeared for TAT-hexaDOPO (Fig. 1d) and TATenneaDOPO (Fig. 1e). The new signals located in the range of 3.77-4.68 ppm for TAT-DOPO compounds were assigned to methylene protons in the $-\mathrm{N}-\mathrm{CH}_{2}-\mathrm{DOPO}$ group. In the ${ }^{31} \mathrm{P} \mathrm{NMR}$ spectra (Fig. 1f-i), TAT-triDOPO and TAT-hexaDOPO displayed single peak at $32.42 \mathrm{ppm}$ and $32.01 \mathrm{ppm}$, respectively, while DOPO itself only had one characteristic signal at $14.50 \mathrm{ppm}$. It can be seen from Fig. 1i that TAT-enneaDOPO displayed two signals at $31.10 \mathrm{ppm}$ and $29.23 \mathrm{ppm}$, which was caused by DOPO unit in different spatial environments. ${ }^{18,29}$ Based on NMR data, it proved that the three compounds of TAT-triDOPO, TAThexaDOPO and TAT-enneaDOPO had been successfully synthesized.

The FTIR spectra of DOPO, TAT and TAT-triDOPO were shown in Fig. 2a. It can be seen that the absorption peak at 

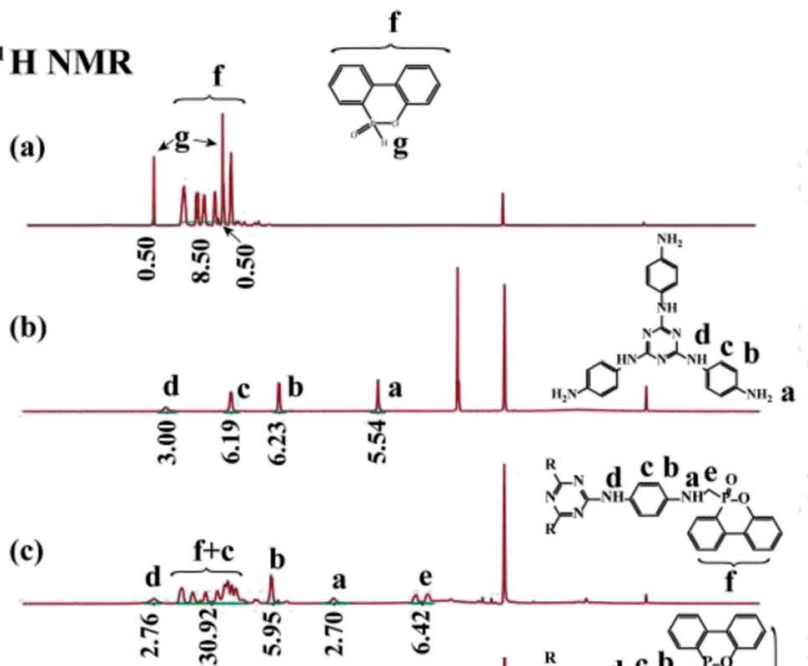

(d)
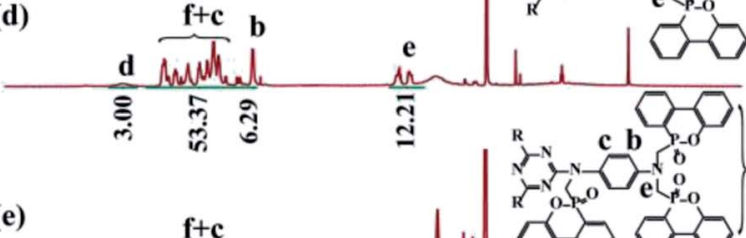

(e)

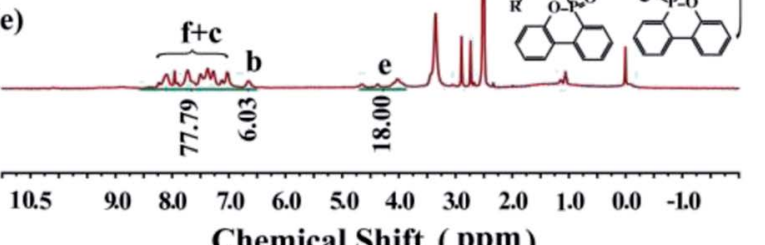

${ }^{31}$ P NMR

(f)

14.50

32.42

(g)

32.01

(h)

31.10

29.23

(i)

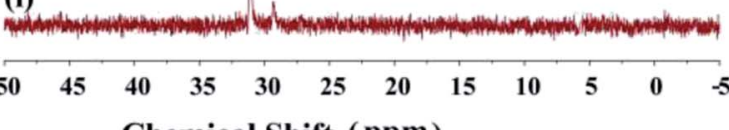

Chemical Shift (ppm)

Fig. $1{ }^{1} \mathrm{H}$ NMR spectra of (a) DOPO, (b) TAT, (c) TAT-triDOPO, (d) TAT-hexaDOPO, and (e) TAT-enneaDOPO; ${ }^{31} \mathrm{P}$ NMR spectra of (f) DOPO, (g) TAT-triDOPO, (h) TAT-hexaDOPO, and (i) TAT-enneaDOPO.

$2386 \mathrm{~cm}^{-1}$ of P-H bond in DOPO disappeared in TAT-triDOPO, indicating the complete reaction of DOPO. The absorption peaks of $\mathrm{P}=\mathrm{O}$ at $1276 \mathrm{~cm}^{-1}$ and $\mathrm{Ph}-\mathrm{O}-\mathrm{P}$ at $910 \mathrm{~cm}^{-1}$ in TATtriDOPO confirmed the presence of DOPO units. ${ }^{30}$ Meanwhile, the absorption peaks of $-\mathrm{NH}_{2}\left(3427 \mathrm{~cm}^{-1}\right.$ and $\left.3389 \mathrm{~cm}^{-1}\right)$ in
TAT dissappeared in TAT-triDOPO, while the absorption peaks of $-\mathrm{NH}-\left(3334 \mathrm{~cm}^{-1}\right.$ and $\left.3219 \mathrm{~cm}^{-1}\right)$ changed to a broaden peak with the absorption of $3314 \mathrm{~cm}^{-1}$. Furthermore, the absorption peaks at $1510 \mathrm{~cm}^{-1}$ and $1081 \mathrm{~cm}^{-1}$ corresponding to triazine ring skeleton were observed in TAT-triDOPO. This also (a) IR

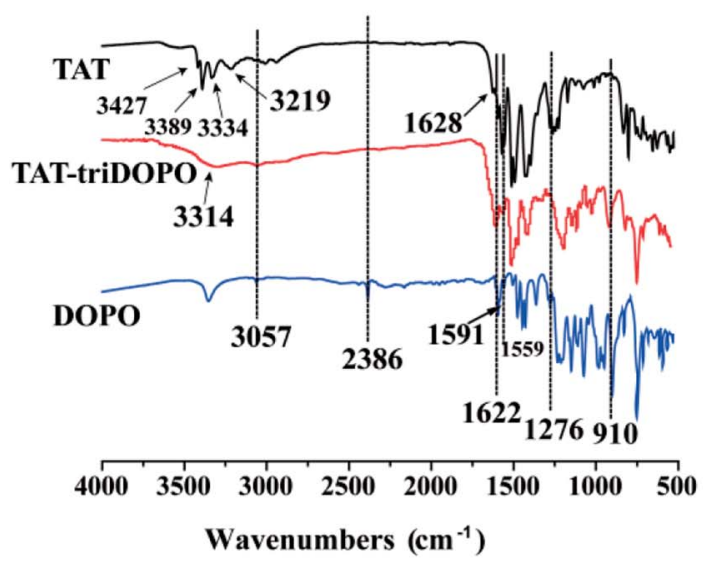

(b) MS
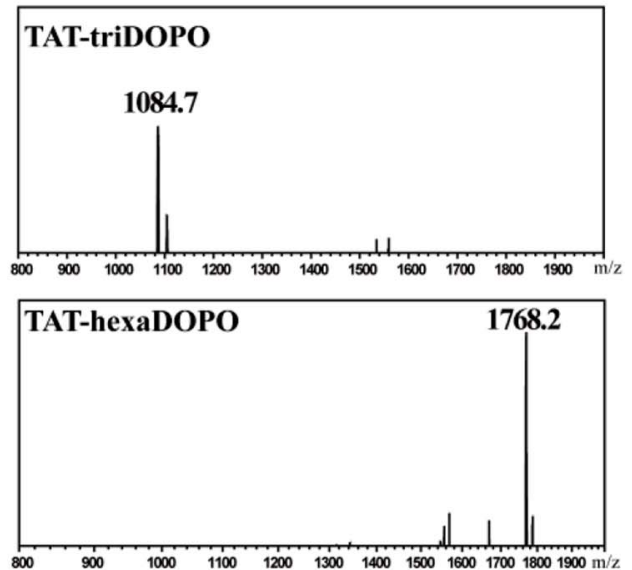

Fig. 2 (a) FTIR spectra of TAT, DOPO and TAT-triDOPO; (b) mass spectra of TAT-triDOPO and TAT-hexaDOPO. 
(a)

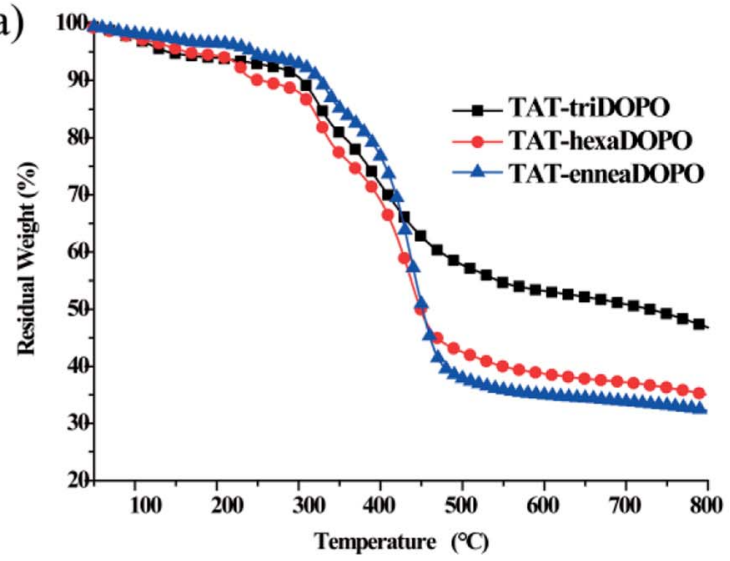

(b)

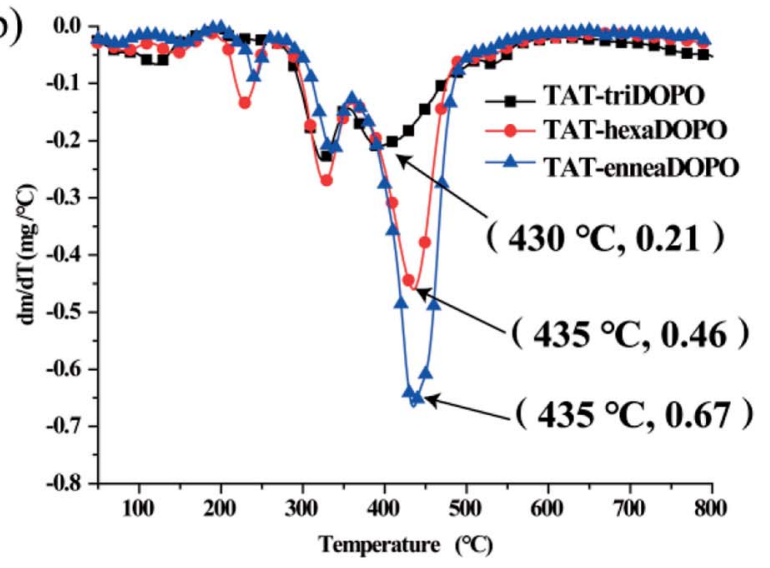

Fig. 3 (a) TGA curves and (b) DTG curves of TAT-triDOPO, TAT-hexaDOPO and TAT-enneaDOPO under $\mathrm{N}_{2}$ atmosphere.

approved the successful synthesis of TAT-triDOPO by the combination of TAT and DOPO via Kabachnik-Fields reaction, which was consistent with NMR results.

ESI-MS was applied to further verify the results of chemical structure deduced from NMR and FTIR. The identified molecular ions corresponded to ionization with $\mathrm{H}^{+}$. It can be found from Fig. $2 \mathrm{~b}$ that the peak with $\mathrm{m} / \mathrm{z} 1084.7$ was assigned to the target product [TAT-triDOPO- $\mathrm{H}^{+}$], while the peak with $\mathrm{m} / \mathrm{z}$ 1768.2 was assigned to the target product [TAT-hexaDOPO- $\mathrm{H}^{+}$] under the testing mode. It was consistent with the calculated molecular weight of TAT-triDOPO $\left(\mathrm{C}_{60} \mathrm{H}_{48} \mathrm{~N}_{9} \mathrm{O}_{6} \mathrm{P}_{3}\right)$ and TAThexaDOPO $\left(\mathrm{C}_{99} \mathrm{H}_{75} \mathrm{~N}_{9} \mathrm{O}_{12} \mathrm{P}_{6}\right)$. We had to mention that TATenneaDOPO had a relative large molecular of 2451 beyond the detection limit of ESI-MS, so that the spectrum of TATenneaDOPO was not presented. In a word, based on the above results of NMR, FTIR and ESI-MS, it was deduced that the target compounds of TAT-DOPO had been successfully obtained.

\subsection{Heat resistance of TAT-DOPO}

The heat resistances of TAT-triDOPO, TAT-hexaDOPO and TATenneaDOPO under nitrogen atmosphere were measured by TGA. The curves of TGA and DTG were displayed in Fig. 3. It can be seen that the temperature range of weight loss was divided into three parts, corresponding to $150-290{ }^{\circ} \mathrm{C}, 290-380^{\circ} \mathrm{C}$ and
$380-560{ }^{\circ} \mathrm{C}$, respectively. The weight loss may be caused by the bond breakdown of the weak bonds such as $\mathrm{P}-\mathrm{O}-\mathrm{C}$ and $\mathrm{P}-\mathrm{C}$, the dissociation of triazine ring, and the escape of small molecular fragments or free radicals. ${ }^{18,27,31}$ During thermal degradation process, the maximum weight loss rate of TAT-triDOPO was the smallest one among the three TAT-DOPO compounds. DTG results showed that when the degradation temperature was above $400{ }^{\circ} \mathrm{C}$, the maximum weight loss rates of TAT-triDOPO, TAT-hexaDOPO and TAT-enneaDOPO were $0.21,0.46$ and $0.67 \mathrm{wt} \% \mathrm{~min}^{-1}$, respectively. In addition, the char residue of TAT-triDOPO was as high as $46.8 \%$, while the char residue of TAT-hexaDOPO and TAT-enneaDOPO was $35.0 \%$ and $32.2 \%$, respectively. These results indicated that the thermal stability of TAT-triDOPO was better than TAT-hexaDOPO and TATenneaDOPO, which would expect TAT-triDOPO to play a good effect in the modification of epoxy resins.

From the view of molecular structure, the three TAT-DOPO compounds had one similar design concept with the intramolecular integration of TAT center and DOPO units, although TAT-triDOPO had one TAT center and three DOPO units per molecule, while TAT-hexaDOPO and TAT-enneaDOPO had six DOPO units and nine DOPO units. Based on the above heat-resistance results, TAT-triDOPO exhibited the best thermal stability. In order to investigate the advantage of this intramolecular design, we took TAT-triDOPO molecule to further
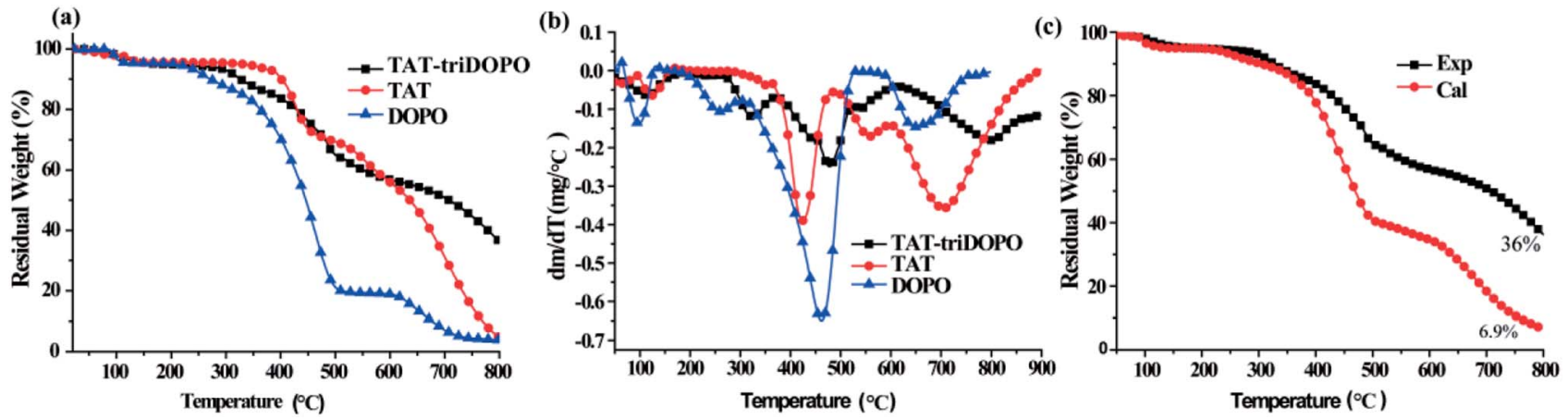

Fig. 4 (a) TGA and (b) DTG curves of TAT-triDOPO, TAT and DOPO under air atmosphere; (c) the calculated and experimental data of residue in TAT-triDOPO. 
Table 1 Thermal decomposition data of TAT, DOPO and TAT-triDOPO. (R: wt\% $\mathrm{min}^{-1}$ )

\begin{tabular}{llllr}
\hline Sample & $R_{1} / T_{\max 1}$ & $R_{2} / T_{\max 2}$ & $R_{3} / T_{\max 3}$ & $R_{4} / T_{\max 4}$ \\
\hline TAT & $0.07 / 126^{\circ} \mathrm{C}$ & $0.39 / 425{ }^{\circ} \mathrm{C}$ & $0.17 / 560{ }^{\circ} \mathrm{C}$ & $0.36 / 706{ }^{\circ} \mathrm{C}$ \\
DOPO & $0.14 / 97^{\circ} \mathrm{C}$ & $0.12 / 258^{\circ} \mathrm{C}$ & $0.65 / 462{ }^{\circ} \mathrm{C}$ & $0.15 / 652{ }^{\circ} \mathrm{C}$ \\
TAT-triDOPO & $0.06 / 113{ }^{\circ} \mathrm{C}$ & $0.12 / 324^{\circ} \mathrm{C}$ & $0.24 / 479{ }^{\circ} \mathrm{C}$ & 4.8 \\
\end{tabular}

conduct the comparison of thermal stability between TAT, DOPO and TAT-triDOPO. The TGA and DTG curves of TATtriDOPO, TAT and DOPO under air atmosphere were shown in Fig. 4. The maximum weight loss rate $R$, the decomposition temperature at the maximum weight loss rate $\left(T_{\max }\right)$, and char yield at $800{ }^{\circ} \mathrm{C}$ were summarized in Table 1 . It could be seen from Fig. 4(a and b) that the thermal degradation of TATtriDOPO at air atmosphere was complicated because oxygen was an important factor to accelerate the thermal degradation. The whole degradation process of TAT-triDOPO, TAT and DOPO included four stages. It was obvious that DOPO was the easiest one to decompose because it had the lowest decomposition temperature at each stage. In the temperature range of 300$550{ }^{\circ} \mathrm{C}$, the maximum weight loss rate of DOPO with a value of $0.65 \mathrm{wt} \% \mathrm{~min}^{-1}$ was bigger than those of TAT and TAT-DOPO. It was explained by the existence of weak bonds of $\mathrm{P}-\mathrm{O}-\mathrm{C}$ and $\mathrm{P}-\mathrm{C}$ in DOPO. As for TAT, when the temperature was heated to above $500{ }^{\circ} \mathrm{C}$, its maximum weight loss rate reached the highest value of $0.36 \mathrm{wt} \% \mathrm{~min}^{-1}$ due to the decomposition of triazine ring. Compared with DOPO and TAT, TAT-triDOPO exhibited a relatively low decomposition rate. It was worth noting that at $800{ }^{\circ} \mathrm{C}$ the carbon residue of TAT, DOPO and TAT-triDOPO were $4.8 \%$, $3.9 \%$ and $36 \%$, respectively. This indicated that the integration of DOPO with TAT by covalent bonds could not only improve the thermal stability of DOPO units, but also produce synergistic effect which was helpful to form more stable compounds during the process of pyrolysis. Furthermore, in order to get more understanding on the synergistic effect, we continued to compare the experimental data and theoretical calculation of the thermal-oxidative decomposition. We carried out the theoretical calculation by calculating the sum of TAT and DOPO. The formula of the theoretical residual weight was expressed by
$\mathrm{Char}_{\text {cal }}=\mathrm{TAT}_{\text {exp }} \times \mathrm{wt} \%+\mathrm{DOPO}_{\text {exp }} \times \mathrm{wt} \% .^{32}$ As shown in Fig. 4c, the theoretical carbon residue of TAT-triDOPO was $6.9 \%$, and the experimental carbon residue of TAT-triDOPO was $36 \%$. The experimental result was much higher than that of theoretical calculation. It implied that the thermal stability of TAT-triDOPO from the integration of DOPO with TAT by covalent bonds was much better than the simple mixture of TAT and DOPO. This proved the existence of phosphorus-nitrogen synergistic effect in the designed molecules.

\subsection{Curing reactivity of TAT-DOPO}

In order to get more understanding of the chemical property of the synthesized TAT-DOPO flame retardants, DSC was used to record the curing reactivity of TAT-triDOPO, TAT-hexaDOPO and TATenneaDOPO with diglycidyl ether of bisphenol A (DGEBA). Fig. 5a showed the curing curves without the addition of usual curing-agent DDM. It can be seen that the mixture of DGEBA/TATtriDOPO displayed an exothermic peak at about $120^{\circ} \mathrm{C}$, which was caused by the reaction of - $\mathrm{NH}$ - in TAT-triDOPO with the epoxy groups in DGEBA..$^{20,33}$ Compared with the mixture of DGEBA/TATtriDOPO, the exothermic peak of DGEBA/TAT-hexaDOPO shifted to about $135{ }^{\circ} \mathrm{C}$ because TAT-hexaDOPO possessed more DOPO units per molecule than TAT-triDOPO did. More DOPO units, stronger steric hindrance. The steric effect led to a higher reaction temperature for the reaction between TAT-hexaDOPO and DGEBA. However, for the mixture of DGEBA/TAT-enneaDOPO, the exothermic peak almost disappeared due to no chemical reaction. The variation in the exothermic behavior was ascribed to the numbers of active hydrogen atoms in the three compounds. In detail, TAT-triDOPO had six-NH- groups and TAT-hexaDOPO only had three - NH- groups, resulting in less curing reactivity for TAThexaDOPO than TAT-triDOPO. Because TAT-enneaDOPO did not
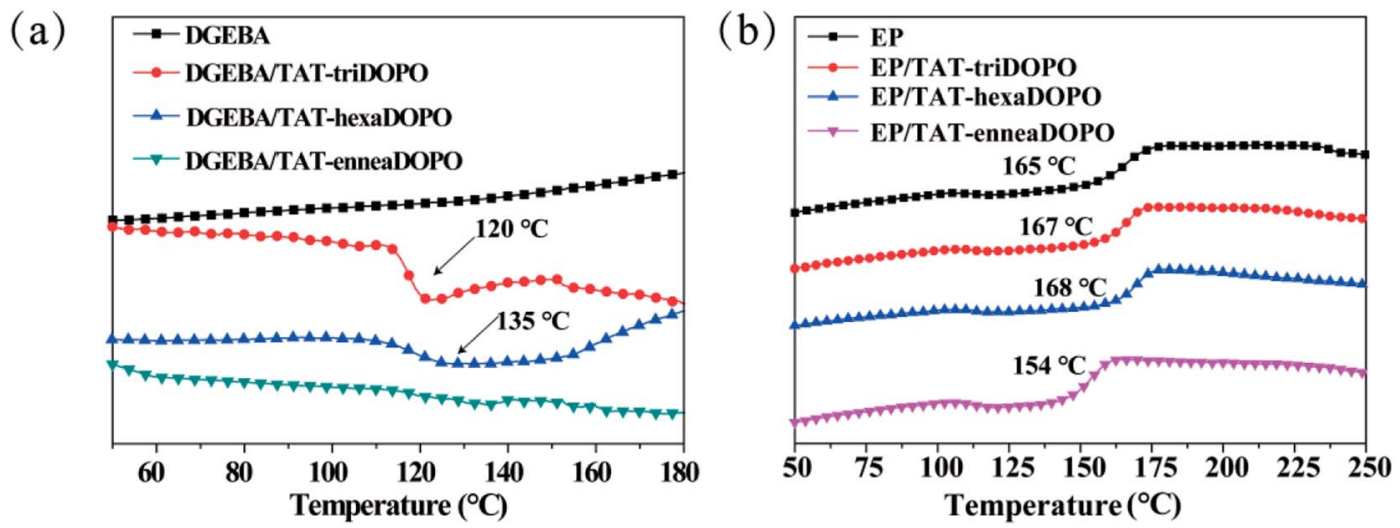

Fig. 5 (a) The DSC curing curves of DGEBA, DGEBA/TAT-triDOPO, DGEBA/TAT-hexaDOPO, and DGEBA/TAT-enneaDOPO without adding DDM; (b) the DSC curves of the cured epoxy resins with adding DDM. 
have any - NH- group, no chemical reaction happened between DGEBA and TAT-enneaDOPO. Both TAT-triDOPO and TAThexaDOPO could react with the epoxy groups to participate in the curing reaction of DGEBA, therefore, they belonged to the reactive-type flame retardant, but TAT-enneaDOPO belonged to a kind of additive-type flame retardant.

Since the curing activities of the three TAT-DOPO compounds were different, their influences on the modified EP thermosets were further investigated by DSC. The glass transition temperature is an important parameter for the application of EP thermosets. Here, the cured EP/TAT-DOPO samples with stoichiometric weight of curing-agent DDM were prepared by the general curing program under high temperature, and the DSC curves of the different cured EP samples were shown in Fig. 5b. It is known that the glass transition is ascribed to the segmental motion of polymeric networks, and $T_{\mathrm{g}}$ is determined by the degree of freedom for segmental motion, crosslinking and entanglement constraints of polymer chains. Fig. 5b showed that the $T_{\mathrm{g}}$ value of neat cured EP was $165{ }^{\circ} \mathrm{C}$, while that of EP/TATenneaDOPO decreased to $154{ }^{\circ} \mathrm{C}$. It was explained that the incorporation of the additive-type TAT-enneaDOPO possessing several rigid benzene rings led to the increasing of the free volume of epoxy resins, which enlarged the motion space and improved the motion ability of segmers, thus resulting in a decline of $T_{\mathrm{g}}$. However, it was noteworthy that the cured EP/ TAT-triDOPO and EP/TAT-hexaDOPO thermosets displayed a little higher $T_{\mathrm{g}}$ values of $167{ }^{\circ} \mathrm{C}$ and $168{ }^{\circ} \mathrm{C}$ than that of neat cured EP. It was explained that the reactive-type TAT-triDOPO and TAT-hexaDOPO could easily participate in curing reaction, serve as cross-linking agent to increase the cross-linking density of EP, and then increase the $T_{\mathrm{g}}$ values of the modified EP.

\subsection{Thermal properties of the cured epoxy resins}

TGA tests were also carried out to investigate the thermal stability and decomposition behavior of the cured epoxy resins. The TGA and DTG curves under both air and $\mathrm{N}_{2}$ atmospheres were shown in Fig. 6 and the relative thermal decomposition data were summarized in Table 2. As shown in Fig. 6a, under air atmosphere the whole degradation process of all the cured EP samples could be divided into two stages. However, under $\mathrm{N}_{2}$ atmosphere the degradation of all the cured EP samples finished completely in only one stage, as displayed in Fig. 6b. Because of the thermal-oxidative interaction, the initial decomposition temperatures $T_{\mathrm{d}}$ of all the samples under air atmosphere were lower than those in $\mathrm{N}_{2}$ atmosphere. It can be seen from Fig. 6a that the first decomposition process of all samples appeared at around $300{ }^{\circ} \mathrm{C}$, implying that the same thermal decomposition pathway occurred to these samples. This was probably induced by the dehydrogenation and aromatization of alkyl groups in the range of $220-375^{\circ} \mathrm{C}^{29}$ The second degradation stage appeared at $375-725{ }^{\circ} \mathrm{C}$, which was considered to be the thermo-oxidative degradation of the unstable carbon layer resulting from the first stage of degradation. During the thermal degradation process, the nitrogencontaining segments of TAT-DOPO might generate gas molecules and triazine skeleton structures, and the phosphoruscontaining segments might produce phosphorus-based (a)
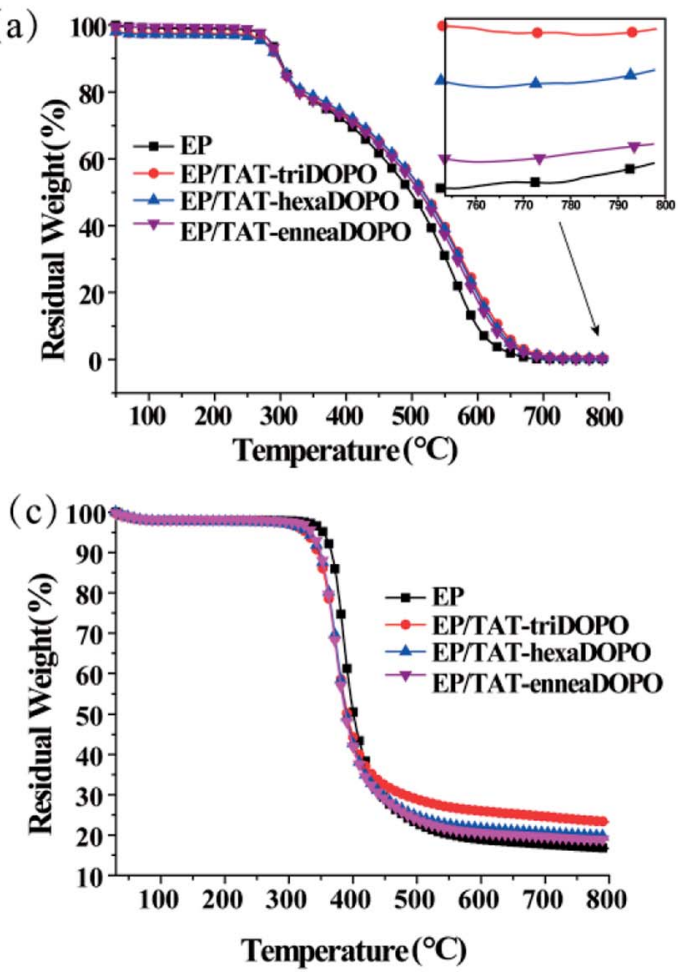
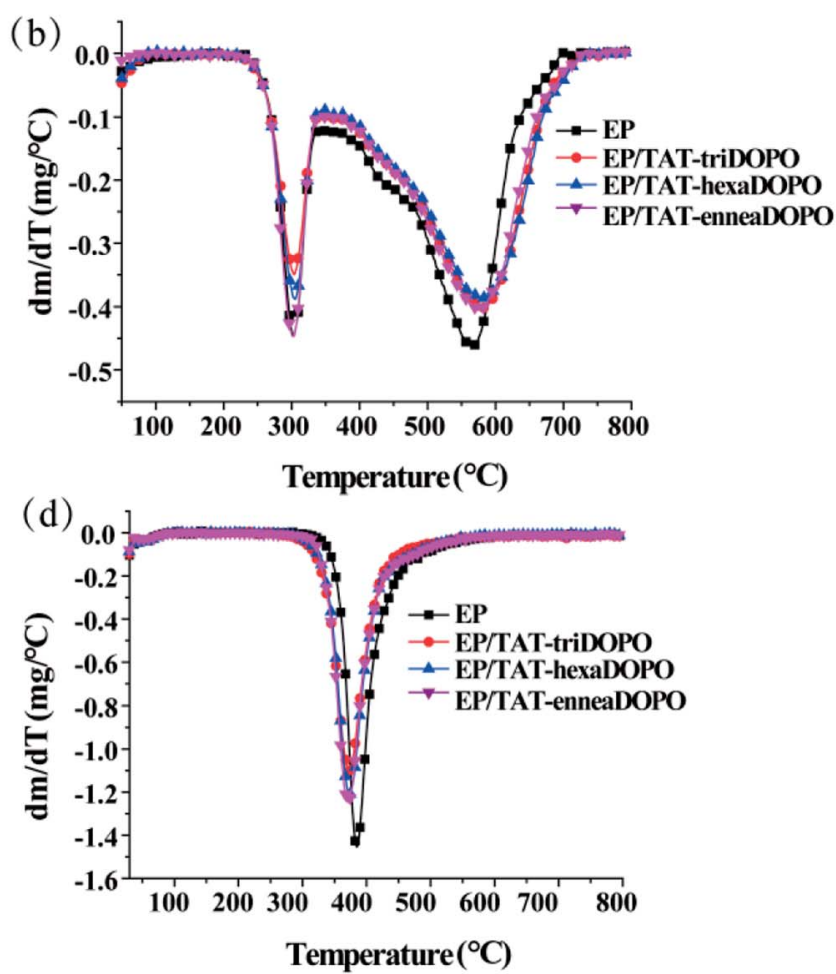

Fig. 6 TGA curves of the cured EP composites under (a) air and (b) $N_{2}$; DTG curves of the cured EP composites under (c) air and (d) $N_{2}$ atmospheres. 
Table 2 Thermal decomposition data of the cured epoxy resins

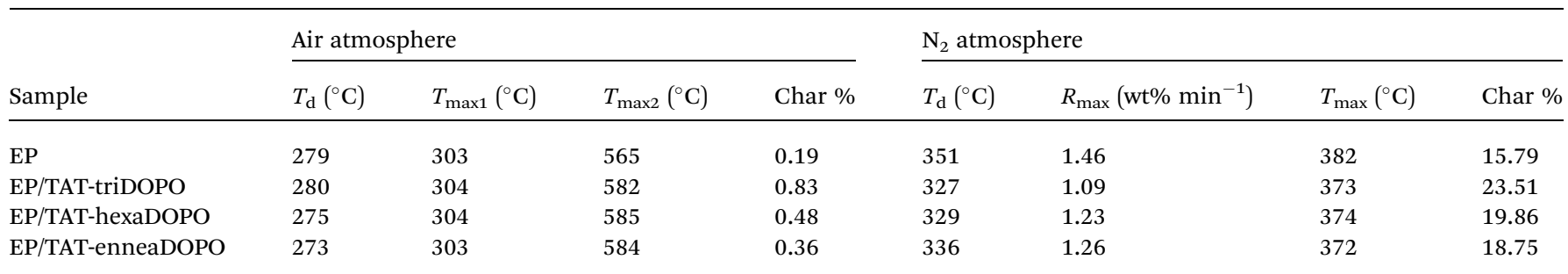

Table 3 LOI values and UL-94 data of the cured epoxy resin

\begin{tabular}{lllrll}
\hline & & \multicolumn{2}{l}{ UL-94 } \\
\cline { 3 - 6 } Samples & LOI (\%) & Burning grade & $t_{1}(\mathrm{~s})$ & $t_{2}(\mathrm{~s})$ & Dripping \\
\hline EP & 26.2 & NR & $>30$ & - & Yes \\
EP/TAT-triDOPO & 34.0 & V-0 & 1 & 1 & No \\
EP/TAT-hexaDOPO & 32.8 & V-0 & 1 & 1 & No \\
EP/TAT-enneaDOPO & 32.1 & V-1 & 24 & 2 & No \\
\hline
\end{tabular}

radicals and polyphosphoric acid. The possible inert gases and phosphorus-based radicals could act in the vapor phase to interrupt the combustion process of EP composites. Simultaneously some solid layers containing polyphosphoric acid and triazine compounds formed at the surface of EP matrix. The char layers acted as physical barrier, which hindered combustible volatiles and heat transfer between the gas and condensed phases, and then prevented the EP matrix from further combustion. In addition, Fig. $6 \mathrm{c}$ and Table 2 showed that for $\mathrm{EP} /$ TAT-triDOPO, EP/TAT-hexaDOPO and EP/TAT-enneaDOPO, the temperature of maximum weight loss rate at the second stage $\left(T_{\max 2}\right)$ were 582,585 and $584{ }^{\circ} \mathrm{C}$, respectively, which was higher than pure EP thermoset with a $T_{\max 2}$ value of $565{ }^{\circ} \mathrm{C}$. This implied that the first pyrolysis products of TAT-DOPO could effectively improve the thermal stability of the EP/TAT-DOPO thermosets.

As shown in Fig. 6(b and d), under $\mathrm{N}_{2}$ atmosphere, the $T_{\mathrm{d}}$, $T_{\max }$ and maximum weight loss rate of pure EP were around $351{ }^{\circ} \mathrm{C}, 382{ }^{\circ} \mathrm{C}$, and $1.46 \mathrm{wt} \% \mathrm{~min}^{-1}$, respectively. However, the $T_{\mathrm{d}}$ and $T_{\max }$ values of all the modified samples decreased slightly, which mainly caused by the decomposition of weak bonds ( $\mathrm{P}-\mathrm{O}-\mathrm{C}$ and $\mathrm{P}-\mathrm{C})$ in DOPO unit. ${ }^{20}$ The maximum weight loss rates of cured EP/TAT-triDOPO, EP/TAT-hexaDOPO and EP/ TAT-enneaDOPO were 1.09, 1.23 and $1.26 \mathrm{wt} \% \mathrm{~min}^{-1}$, respectively. Obviously the maximum weight loss rates of the EP/TATDOPO composites were lower than that of pure EP. Furthermore, the char residue of cured EP/TAT-triDOPO, EP/TAThexaDOPO and EP/TAT-enneaDOPO composites at $800{ }^{\circ} \mathrm{C}$ were increased to $23.51 \%, 19.86 \%$ and $18.75 \%$, respectively, in comparison with $15.79 \%$ of pure EP. These results showed that the incorporation of TAT-DOPO could reduce the maximum weight loss rate of EP/TAT-DOPO composites and promote the char formation in the process of thermal degradation. Overall, the three kinds of flame retardants could improve the thermal stability of epoxy resin to some extent. Among the three TATDOPO compounds, the addition of TAT-triDOPO with the ratio of phosphorus to nitrogen being 0.74 played the best optimal effect on the thermal stability of cured EP/TAT-DOPO materials at a low phosphorus content of $0.43 \%$.

\subsection{Flame retardancy of the cured epoxy resins}

The flame retardancy of the cured epoxy resins was measured by LOI and UL-94 vertical burning tests and the concerned data were illustrated in Table 3. It can be seen that the LOI of pure EP was $26.2 \%$, while the LOI values of the cured EP/TAT-triDOPO, EP/TAT-hexaDOPO and EP/TAT-enneaDOPO composites were increased to $34.0 \%, 32.8 \%$ and $32.1 \%$, respectively. Both the cured EP/TAT-triDOPO and EP/TAT-hexaDOPO passed through the UL-94 V-0 rating with no dripping and exhibited selfextinguishing. But the cured EP/TAT-enneaDOPO only achieved a UL-94 V-1 rating. These results indicated that the incorporation of TAT-DOPO could improve the flame retardancy of the EP thermosets, and the coexistence of phosphorous and nitrogen in TAT-DOPO played synergistic flame retardant effect.

The heat release rate (HRR) curves of the cured epoxy resins were demonstrated in Fig. 7, the peak heat release rate (PHHR), the total heat release (THR) and the heat release capability (HRC) were listed in Table 4. It was worth noting that the values of PHHR, THR and HRC of the cured epoxy resins showed the similar trend as the results of LOI test. The PHHR and the THR of pure EP were $452.9 \mathrm{~W} \mathrm{~g}^{-1}$ and $25.1 \mathrm{~kJ} \mathrm{~g}^{-1}$, respectively. When TAT-triDOPO was added, the PHHR and the THR of EP/TATtriDOPO decreased to $336.4 \mathrm{~W} \mathrm{~g}^{-1}$ and $19.8 \mathrm{~kJ} \mathrm{~g}^{-1}$, respectively. Furthermore, the HRC of EP/TAT-triDOPO also

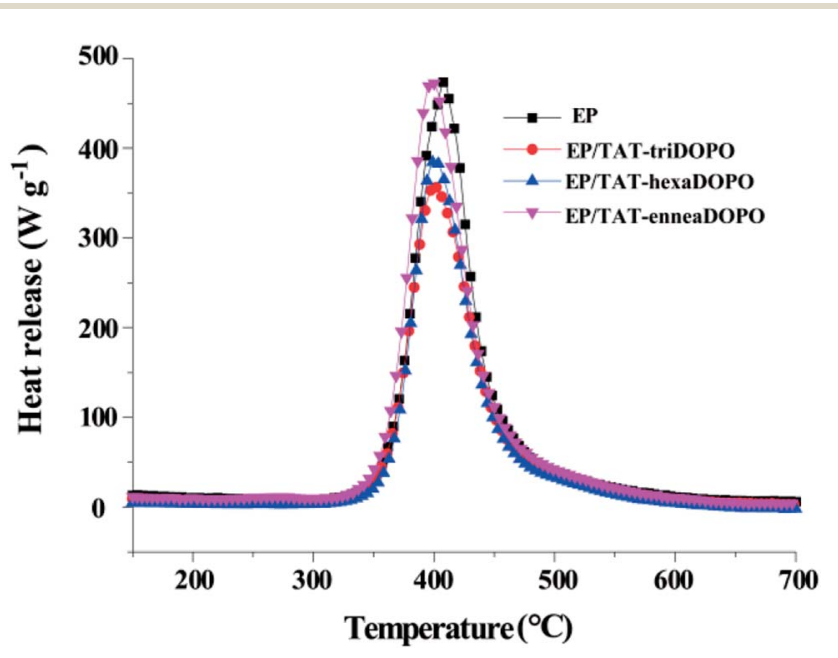

Fig. 7 HRR curves of the cured epoxy resins. 
Table 4 Microscale combustion calorimeter data of the cured epoxy resins

\begin{tabular}{llll}
\hline Sample & PHRR $\left(\mathrm{W} \mathrm{g}^{-1}\right)$ & THR $\left(\mathrm{kJ} \mathrm{g}^{-1}\right)$ & $\operatorname{HRC}\left(\mathrm{J} \mathrm{g}^{-1}\right)$ \\
\hline EP & 452.9 & 25.1 & 453 \\
EP/TAT-triDOPO & 336.4 & 19.8 & 338 \\
EP/TAT-hexaDOPO & 368.6 & 20.1 & 370 \\
EP/TAT-enneaDOPO & 448.1 & 24.8 & 450
\end{tabular}

significantly decreased. It could be deduced that the flame retardancy of the cured EP/TAT-triDOPO, EP/TAT-hexaDOPO and EP/TAT-enneaDOPO were better than that of pure EP due to the addition of TAT-DOPO. Among three cured EP/TATDOPO, EP/TAT-triDOPO exhibited the best performance due to the effective synergetic effect of phosphorus and nitrogen.

\subsection{Char residue analysis of the cured epoxy resins}

The microstructure of char residues of the cured epoxy resins were characterized by SEM and shown in Fig. 8. It can be seen from Fig. $8(\mathrm{a}$ and $\mathrm{b})$ that the residual char of pure EP exhibited a granular loose outer layer and a smooth folded sheet-like inner layer. The drawback of this kind of structure was that the heat and oxygen could easily penetrate through this char layer and enter into the inner, consequently increased the combustion intensity. However, from Fig. 8(c, e and g), we found that the char residue of the cured EP/TAT-DOPO displayed a continual and compact exterior char layer, which was helpful to prevent the volatile gas from thermal degradation from spreading. Especially, the exterior char layer of EP/TATtriDOPO contained some holes. It was presumed that the free radicals were hindered by the continuous and compact char residue at first, and finally concentratedly released to exert a strong quenching effect, thus resulting in some holes on the surfaces. Besides, as shown in Fig. 8d, the interior carbon layer of EP/TAT-triDOPO exhibited a honeycomb with some broken bubbles on the surface. The reason for this phenomenon may be that phosphorus-containing compounds produced phosphorus-containing free radicals and polyphosphoric acid, and nitrogen-containing compounds released nitrogencontaining radicals, inert gases, and triazine skeletons. The non-combustible gases were likely to escape to the outside during the combustion process, whereas the viscous carbon layer formed by polyphosphoric acid and triazine skeletons reduced the release rate of the gases, thus formed this kind of honeycomb structure. These special structures could reduce the efficiency of heat and oxygen exchange. The barrier effect of the char layer and strong quenching effect of high concentration of free radicals led to the promoted flame retardant property. However, as for cured EP/TAT-hexaDOPO and EP/TATenneaDOPO samples, the honeycomb structures of the interior carbon layer became smaller and even disappeared. This may be attributed to the decreasing of non-combustible gases during combustion and the reduction of the triazine structure in the condensed phase with the decreasing of nitrogen content in cured EP/TAT-hexaDOPO and EP/TAT-enneaDOPO samples.

\subsection{Investigation of flame retardant mechanism}

In order to investigate the possible flame retardant mechanism for the EP/TAT-triDOPO composites, the thermal degradation and combustion products were analyzed by FTIR. The FTIR spectra of the volatile products produced by EP/TAT-triDOPO around the temperature range at the maximum decomposition rate were presented in Fig. 9a. The main absorption peaks were ascribed to the characteristic bands of water $\left(3646 \mathrm{~cm}^{-1}\right)$, carbon dioxide $\left(2256 \mathrm{~cm}^{-1}\right)$ and compounds containing aromatic ring (1700-1500 $\left.\mathrm{cm}^{-1}\right)$. In addition, the absorption peaks at 1259, 1174 and $1076 \mathrm{~cm}^{-1}$ were attributed to the characteristic absorption peaks of $\mathrm{P}=\mathrm{O}$ and $\mathrm{P}-\mathrm{O}-\mathrm{C}$ in gas. It was obvious that phosphorus-containing products were generated from the cured EP/TAT-triDOPO. The characteristic absorption peaks of C-N and $\mathrm{NH}_{3}$ were observed at 1370, 984 and $925 \mathrm{~cm}^{-1}$, respectively, confirming the formation of ammonia and other nitrogen-containing compounds. ${ }^{34}$ On the basis of the chemical structure of TAT-triDOPO, it could be
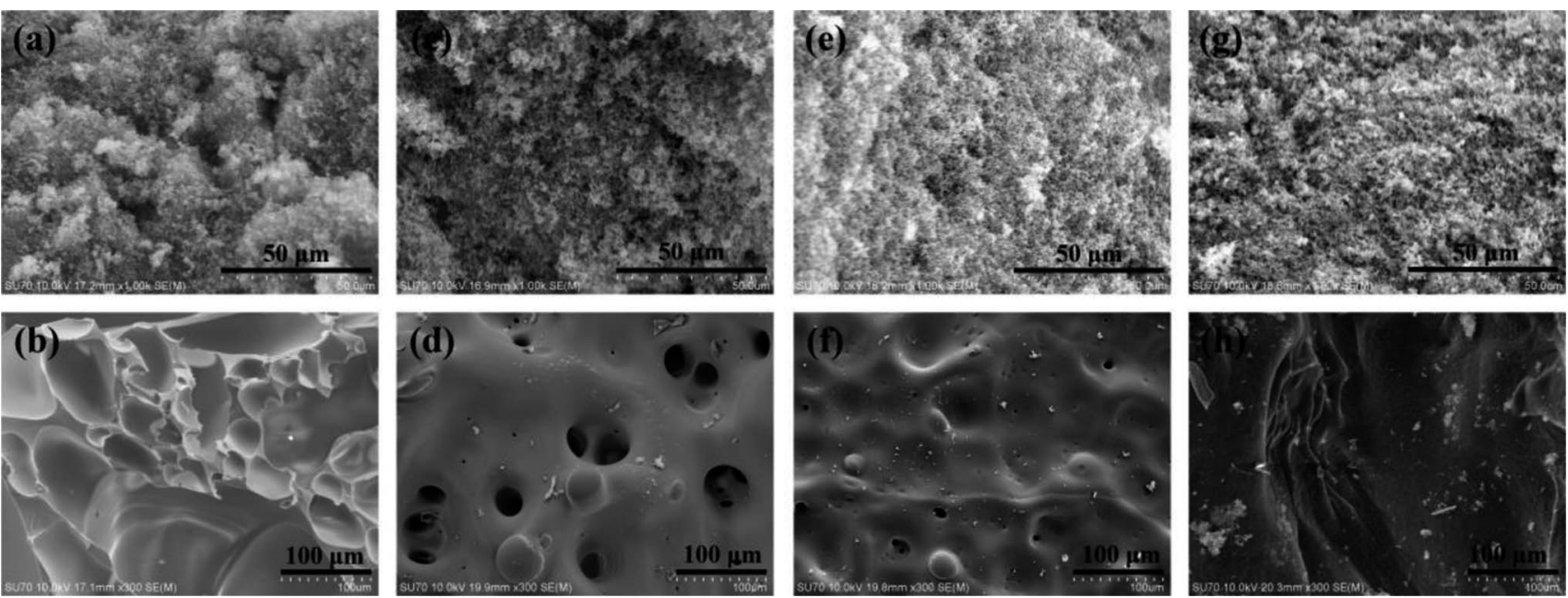

Fig. 8 SEM images of char residue: (a) EP, exterior; (b) EP, interior; (c) EP/TAT-triDOPO, exterior; (d) EP/TAT-triDOPO, interior; (e) EP/TAThexaDOPO, exterior; (f) EP/TAT-hexaDOPO, interior; (g) EP/TAT-enneaDOPO, exterior; (h) EP/TAT-enneaDOPO, interior. 

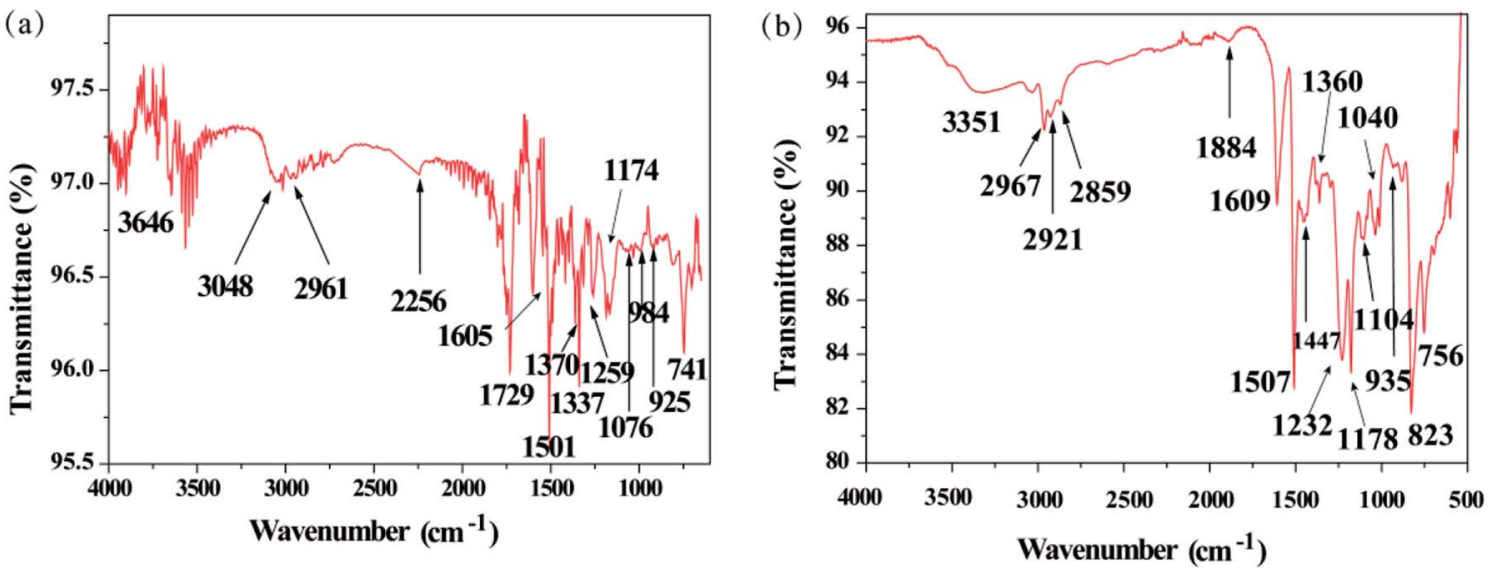

Fig. 9 FTIR spectra of (a) volatiles generated at the maximum decomposition rate, and (b) residual char obtained from UL-94 test for the cured EP/TAT-triDOPO.

deduced that the phosphorus-containing products were generated by the DOPO units and the nitrogen-containing products were produced from the triazine groups. The generated gases could dilute the oxygen concentration, and phosphoruscontaining free radicals could quench other essential active free radicals, and then weaken or terminate the chain reaction, which prevented the matrix from burning. Hence, during combustion of cured EP/TAT-triDOPO, these volatiles products were produced and played an important role in fire inhibition through the gaseous phase.

The FTIR spectra of the char residue of EP/TAT-triDOPO obtained from UL-94 test were demonstrated in Fig. 9b. The peak observed at $3351 \mathrm{~cm}^{-1}$ corresponded to $\mathrm{N}-\mathrm{H}$ and $\mathrm{O}-\mathrm{H}$ stretching vibrations. The peaks at 1447,1510 and $1609 \mathrm{~cm}^{-1}$ corresponded to the absorbance peaks of polyaromatic carbon resulting from the degradation of the cured EP/TAT-triDOPO. The absorbance peaks of $\mathrm{C}-\mathrm{N}$ at $1360 \mathrm{~cm}^{-1}$ and the characteristic peak of triazine ring at $1507 \mathrm{~cm}^{-1}$ (overlapping with that of aromatic carbon) indicated the existence of triazine structure reserved in the residual char. ${ }^{18}$ Meanwhile the characteristic peak at $1104 \mathrm{~cm}^{-1}$ corresponded to the stretching vibrations of $\mathrm{PO}_{2} / \mathrm{PO}_{3}$ from the phosphoric acid carbon composites, and the absorbance peaks at 935 and $756 \mathrm{~cm}^{-1}$ identified the existence of $\mathrm{P}-\mathrm{O}-\mathrm{Ph}$ in the residual char. These results indicated that during the thermal degradation of cured EP/TAT-triDOPO, DOPO groups decomposed to generate phosphate and polyphosphate and the triazine groups remained in the char residue. The different functional groups of TATtriDOPO synergistically acted in the condensed phase to form the phosphorus-rich viscous char layer with triazine groups, which possessed high cross-linking density and thermal stability.

Overall, TAT-triDOPO could improve the flame retardancy of EP thermosets effectively due to the combination of gas phase and condensed phase flame retardant mechanisms. From the view of gas phase mechanism, TAT-triDOPO decomposed and released phosphorus-containing and nitrogen-containing free radicals and inert gases, which played an important role in weakening or terminating the combustion. And when the amount of pyrolysis products exceeded the holding capacity of the char layer, the free radicals were released concentratedly to exert a strong quenching effect. From the view of condensed phase, the TAT-triDOPO decomposed to produce phosphate, polyphosphate and triazine skeleton, which promoted the charring of EP matrix to form the phosphorus-rich viscous char layer with triazine groups. Meanwhile, the residual char played a crucial role in preventing the transfer of heat and oxygen and hindering the combustion greatly. The effect of non-combustion gases, quenching effect of high concentration of free radicals and the barrier effect of the thermally stable char layer were responsible for improving flameretardant performance of the cured EP/TAT-triDOPO.

\subsection{Mechanical properties of cured epoxy resins}

The influence of three TAT-DOPO flame retardants on the mechanical property of the modified EP thermosets was investigated. The mechanical properties of cured epoxy resins were evaluated by dynamic mechanical analysis under double cantilever model. The curves of storage modulus and loss factor $\tan \delta$ were shown in Fig. 10, and the data were also given in the Table 5. The average storage modulus of EP, EP/TAT-triDOPO, $\mathrm{EP} / \mathrm{TAT}$-hexaDOPO and EP/TAT-enneaDOPO at $40{ }^{\circ} \mathrm{C}$ was

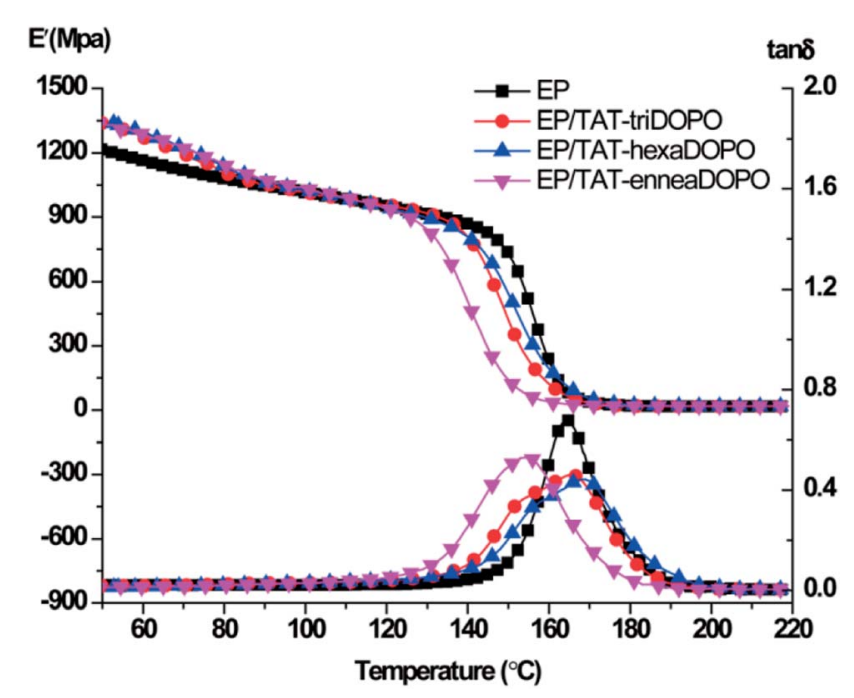

Fig. 10 DMA curves of the cured epoxy resins. 
Table 5 DMA data of the cured epoxy resins

\begin{tabular}{|c|c|c|c|c|}
\hline Sample & $T_{\mathrm{g}} /{ }^{\circ} \mathrm{C}$ & $\mathrm{E}^{\prime}-40^{\circ} \mathrm{C} / \mathrm{MPa}$ & $\mathrm{E}^{\prime}-190^{\circ} \mathrm{C} / \mathrm{MPa}$ & $\tan \delta$ \\
\hline $\mathrm{EP}$ & $164.6 \pm 0.3$ & $1256.7 \pm 18.7$ & $16.8 \pm 0.3$ & $0.67 \pm 0.01$ \\
\hline EP/TAT-triDOPO & $166.4 \pm 0.5$ & $1393.4 \pm 15.9$ & $17.5 \pm 0.2$ & $0.45 \pm 0.01$ \\
\hline EP/TAT-enneaDOPO & $154.6 \pm 0.4$ & $1377.3 \pm 22.5$ & $18.1 \pm 0.3$ & $0.53 \pm 0.01$ \\
\hline
\end{tabular}

Table 6 Flexural strength of cured epoxy resins

\begin{tabular}{lll}
\hline Sample & $\begin{array}{l}\text { Flexural } \\
\text { strength (MPa) }\end{array}$ & $\begin{array}{l}\text { Percentage of increased } \\
\text { flexural strength }(\%)\end{array}$ \\
\hline EP & $70.02 \pm 4.03$ & 0 \\
EP/TAT-triDOPO & $79.67 \pm 3.07$ & 13.8 \\
EP/TAT-hexaDOPO & $66.39 \pm 3.98$ & -5.1 \\
EP/TAT-enneaDOPO & $69.08 \pm 3.37$ & -1.3 \\
\hline
\end{tabular}

1256.7, 1393.4, 1347.4 and 1377.3 $\mathrm{MPa}$, respectively. This implied that at glass state, the incorporation of TAT-DOPO could enhance the dynamic mechanical properties of the cured EP/TAT-DOPO. When the temperature increased to $190{ }^{\circ} \mathrm{C}$, the EP thermosets were transformed into a rubber state. The average storage modulus of pure EP was 16.8 MPa, while those of EP/TAT-DOPO thermosets increased to 17.5, 19.6 and 18.1 MPa, respectively, indicating all the storage modulus of the cured EP/TAT-DOPO were enhanced to a higher level compared with pure EP. It was explained that the rigid macromolecular structures of TAT-enneaDOPO could act as physical crosslinking points. Meanwhile TAT-triDOPO and TAT-hexaDOPO with active hydrogen could act as chemical crosslinking points, and then enhanced the storage modulus of the EP composites under the rubber state.

In order to further investigate the mechanical property of the cured epoxy resins, three-point bending tests were adopted to measure the flexural strengths and the data were demonstrated in Table 6. The results showed that the flexural strength of pure EP was about $70.02 \mathrm{MPa}$ while that of EP/TAT-triDOPO was $79.67 \mathrm{MPa}$. The percentage of increased flexural strength was about $13.8 \%$. This improvement may be attributed to the active hydrogen atoms in TAT-triDOPO molecules acting as effective chemical cross-linking points. However, the addition of TAThexaDOPO and TAT-enneaDOPO led to a decrease in the flexural strength. It was explained that TAT-hexaDOPO and TATenneaDOPO had less active hydrogen atoms and had more rigid benzene rings with strong space steric hindrance, resulting in the reduction of cross-linking density of the modified EP composites. Based on the DMA and three-point test results, the EP/TAT-triDOPO thermoset was the best one to have the potential application in some fields with the requirement of high flame retardancy and good mechanical property.

\section{Conclusions}

Three novel TAT-DOPO compounds possessing the functional groups of phosphaphenanthrene and triazine were successfully synthesized via classical Kabachnik-Fields reaction. TAT-
triDOPO had one TAT center and three DOPO units in one molecule, while TAT-hexaDOPO and TAT-enneaDOPO had six DOPO units and nine DOPO units. All the three compounds were used as flame retardant to modify epoxy resins. It was interesting that TAT-triDOPO and TAT-hexaDOPO displayed the characteristics of reactive-type retardant, while TATenneaDOPO represented additive-type retardant. Besides, TATtriDOPO with the $\mathrm{P} / \mathrm{N}$ ratio of 0.74 exhibited the best thermal stability and curing activity with DGEBA. Compared with the pure EP, the LOI value and char yields of the cured EP/TATDOPO composites were both increased and EP/TAT-triDOPO was the most remarkably promoted one. The LOI value and the UL-94 ratings of the cured EP/TAT-triDOPO with a 5\% loading were raised up to $34.0 \%$ and V-0 grade. Meanwhile, the PHRR, THR and HRC of the cured EP/TAT-triDOPO were decreased by $25.7 \%, 21.1 \%$ and $25.4 \%$, respectively. The mechanical performance tests showed that the incorporation of TAT-triDOPO could also improve both the flexural strength and the elastic modulus of the modified EP/TAT-triDOPO. This may be attributed to the existence of active hydrogen atoms within TAT-triDOPO molecule, which could act as effective chemical cross-linking points in EP network. Finally, based on the SEM and TGA-FTIR analysis of pyrolytic products of cured EP/TATDOPO composites, it was deduced that TAT-DOPO flame retardants could exhibit both condensed phase and gas phase flame-retardancy mechanism. During the combustion, phosphorus-containing and nitrogen-containing free radicals and gases were released, which not only diluted the concentration of combustible gases, but also promoted the expansion of residual char with honeycomb-like morphology. Simultaneously the polyphosphoric acid and compounds with triazine skeleton were generated and covered on the surface of substrate, resulting in forming a protective layer with excellent thermal stability, which effectively hindered the transmission of heat and oxygen and prevented further ablation of substrate. In a word, this work could make contributions to the development of novel flame retardants and could be helpful to get more understandings on the synergistic flame retardancy mechanism of this kind of modified epoxy resins.

\section{Conflicts of interest}

There are no conflicts to declare.

\section{Acknowledgements}

This work was supported by the National Natural Science Foundation of China (51573150), the Natural Science 
Foundation of Fujian Province of China (2018J01079, 2016J01257), and the Xiamen Science and Technology Project (3502Z20183001, 3502Z20183014).

\section{References}

1 J. T. Wan, C. Li, Z. Y. Bu, C. J. Xu, B. G. Li and H. Fan, Chem. Eng. J., 2012, 188, 160-172.

2 J. Jiang, Y. B. Cheng, Y. Liu, Q. Wang, Y. Sh. He and B. W. Wang, J. Mater. Chem. A, 2015, 3, 4284-4290.

3 R. K. Jian, P. Wang, W. S. Duan, J. Sh. Wang, X. L. Zheng and J. B. Weng, Ind. Eng. Chem. Res., 2016, 55, 11520-11527.

4 S. Levchik, A. Piotrowski, E. Weil and Q. Yao, Polym. Degrad. Stab., 2005, 88, 57-62.

5 K. Q. Zhou, R. Gao and X. D. Qian, J. Hazard. Mater., 2017, 338, 343-355.

6 W. Z. Xu, B. L. Zhang, X. L. Wang, G. S. Wang and D. Ding, J. Hazard. Mater., 2017, 343, 364-375.

7 C. S. Wang, J. R. Berman, L. L. Walker and A. Mendoza, J. Appl. Polym. Sci., 1991, 43, 1315-1321.

8 C. Martin, G. Lligadas, J. C. Ronda, M. Galla and V. Cadiz, J. Polym. Sci., Part A: Polym. Chem., 2006, 44, 6332-6344.

9 M. Spontón, J. C. Ronda, M. Galià and V. Cadiz, J. Polym. Sci., Part A: Polym. Chem., 2010, 45, 2142-2151.

10 S. V. Levchik and E. D. Weil, J. Fire Sci., 2006, 24, 345-364.

11 M. J. Xu, G. R. Xu, Y. Leng and L. Bin, Polym. Degrad. Stab., 2016, 123, 105-114.

12 B. R. Zeng, Y. Z. Liu, L. Yang, W. Zheng, T. Chen, G. R. Chen, Y. T. Xu, C. H. Yuan and L. Z. Dai, RSC Adv., 2017, 7, 2608226088.

13 K. A. Salmeia and S. Gaan, Polym. Degrad. Stab., 2015, 113, 119-134.

14 Y. Cao, X. L. Wang, W. Q. Zhang, X. W. Yin, Y. Q. Shi and Y. Z. Wang, Ind. Eng. Chem. Res., 2017, 56, 5913-5924.

15 B. R. Zeng, L. Yang, J. M. Chen, X. Y. Liu, H. Y. Wu, W. Zheng, G. R. Chen, Y. T. Xu and L. Z. Dai, High Perform. Polym., 2017, 1-12.

16 Y. Q. Xiong, X. Y. Zhang, J. Liu, M. M. Li, F. Guo, X. N. Xia and W. J. Xu, J. Appl. Polym. Sci., 2012, 125, 1219-1225.
17 S. Y. Sun, Y. D. He, X. D. Wang and D. Z. Wu, J. Appl. Polym. Sci., 2010, 118, 611-622.

18 S. Yang, J. Wang, S. Q. Huo, M. Wang and L. F. Cheng, Ind. Eng. Chem. Res., 2015, 54, 7777-7786.

19 S. L. Qiu, C. Ma, X. Wang, X. Zhou, X. M. Feng, R. K. K. Yuen and Y. Hu, J. Hazard. Mater., 2017, 344, 839-848.

20 Y. Z. Wang, Y. C. Yuan, Y. Zhao, S. M. Liu and J. Q. Zhao, High Perform. Polym., 2017, 29, 94-103.

21 Q. Zhang, M. Kaisti, A. Prabhu, Y. J. Yu, Y. A. Song, M. H. Rafailovich, A. Rahman and K. Levon, Electrochim. Acta, 2018, 261, 256-264.

22 Q. Zhang, A. Prabhu, A. San, J. F. Al-Sharab and K. Levon, Biosens. Bioelectron., 2015, 72, 100-106.

23 J. Yu, T. C. Zhou, Z. Y. Pang and Q. F. Wei, Text. Res. J., 2016, 86(11), 1171-1179.

24 X. Wang, Y. Hu, L. Song, W. Y. Xing and H. D. Lu, Polym. Adv. Technol., 2012, 23, 190-197.

25 L. J. Qian, Y. Qiu, J. Liu, F. Xin and Y. J. Chen, J. Appl. Polym. Sci., 2014, 131, 39709.

26 S. Yang, Q. X. Zhang and Y. F. Hu, J. Appl. Polym. Sci., 2017, 134, 45291.

27 G. Y. You, Z. Q. Cheng, Y. Y. Tang and H. W. He, Ind. Eng. Chem. Res., 2015, 54, 7309-7319.

28 Z. M. Bai, L. Song, Y. Hu, X. L. Gong and R. K. K. Yuen, J. Anal. Appl. Pyrolysis, 2014, 105, 317-326.

29 B. Zhao, W. Liang, J. Wang, F. Li and Y. Liu, Polym. Degrad. Stab., 2016, 133, 162-173.

30 X. D. Qian, L. Song, B. Yu, B. B. Wang, B. H. Yuan, Y. Q. Shi, Y. Hu and R. K. K. Yuen, J. Mater. Chem. A, 2013, 1, 68226830.

31 Q. Lv, J. Q. Huang, M. J. Chen, J. Zhao, Y. Tan, L. Chen and Y. Z. Wang, Ind. Eng. Chem. Res., 2013, 52, 9397-9404.

32 Y. J. Chen, W. Wang, Z. Q. Liu, Y. Y. Yao and L. J. Qian, J. Appl. Polym. Sci., 2017, 134, 44600.

33 H. M. Wang, Y. C. Zhang, L. R. Zhu, Z. J. Du, B. L. Zhang and Y. Y. Zhang, Thermochim. Acta, 2011, 521, 18-25.

34 R. K. Jian, P. Wang, L. Xia and X. L. Zheng, J. Anal. Appl. Pyrolysis, 2017, 127, 360-368. 